\title{
Classical plant breeding is the route to food security
}

\author{
The right technology in uncertain conditions is one that can manage many subtle traits.
}

Sir - Your unusual and perceptive News Feature "Crop improvement: a dying breed" (Nature 421, 568-570; 2003), on the importance of classical plant breeding, contains an error concerning intellectual property rights applied to plants. Plant breeders' rights, called 'plant variety protection' in the United States, allow and defend the right of plant breeders to use protected varieties as parents in further breeding, contrary to the impression given in your feature. The patent system, not plant breeders' rights, prohibits the use of protected varieties as parents in further breeding. Moreover, utility patents on plants became important only after public plant breeding had already declined.

That decline reflects a sea change in US public policy. From the Civil War until quite recently, agricultural research was seen as a public responsibility, creating public goods. Then, decades of sustained prosperity after the Second World War gave rise to a belief that this was no longer necessary. It was also believed that market forces would supply all the goods that were needed, and that the public sector would be competing with the private sector.

During the same decades, the formerly rural US population became suburban and urban. Public goods of concern to today's policy-makers are the ones that preoccupy urban citizens. These are the reasons behind the decline in support for public plant breeding (see K. J. Frey, National Plant Breeding Study, Iowa Agric. Home Econ. Exp. Station, Ames, Iowa; 1996), as correctly pointed out in your News Feature.

Much as we may consider agriculture to be passé — if we think about it at all — our urban lifestyle depends on a secure supply of abundant, inexpensive, safe and nutritious food. As pointed out in your News Feature, classical plant breeding is the only technology that is currently capable of delivering the secure harvests we require.
This is because only plant breeding can manage many subtle traits at once, as needed to confront challenges of climate change, newly emerging pests and other uncertainties.

Public plant breeding is also a good investment. The rate of return to investment in public plant breeding is $35 \%$ for potatoes in the northwest United States, realized in reduced cost of production and improved food quality as well as in increased yield, according to A. A. Araji and S. Love (Am. J. Potato Res. 79, 411-420; 2002). These results are typical of studies in other crops.

Ann Marie Thro*, Paul Zankowski $\dagger$ ${ }^{*}$ Cooperative State Research, Education, and Extension Service, US Department of Agriculture, 800 9th Street SW, Washington DC 20024, USA $\dagger$ Plant Variety Protection Office, Agricultural Marketing Service, US Department of Agriculture, 10301 Baltimore Boulevard, Beltsville, Maryland 20705-2351, USA

\section{Building bridges through cooperation in science}

Sir - I was heartened to see Nature's Editorial "Time to unite Islam and science" (Nature 422, 99; 2003). Global events since 11 September 2001 have given a new sense of urgency to the Third World Academy of Science's efforts, over the past 20 years, to make science a core part of national policies in countries in these regions.

Although there is woefully inadequate investment in science and education in many predominantly Muslim countries, along with poor rates of economic development and a growing sense of despair and frustration, discussion should focus not on where to assign blame but on strategies for easing the tension and pointing to a better future.

Two aspects of the workshop held in Trieste in March (see Nature 422, 101; 2003) that were described in your Editorial offer small but useful clues on how to move forward.

First, the workshop was jointly funded by the US National Academy of Sciences and, to a lesser extent, the Organization of Islamic Conference Standing Committee on Scientific and Technological Cooperation, and the Islamic Educational, Scientific and Cultural Organization. This is an example of North-South scientific cooperation that could have a positive impact on future relations between these countries on issues related to science and development. More partnerships are needed between cultures that have too often chosen to emphasize their differences rather than their similarities.

Second, the workshop recommended that scientific communities in Muslim countries should increase their mutual cooperation by the creation of a network of science academies for scientific exchange, education and training, and by joint research programmes in areas of critical concern to Muslim countries. This is an example of South-South cooperation that holds the key for future success in efforts to advance science-based development.

North-South and, more important, South-South scientific cooperation could help forge alliances of mutual concern that will help to ease apprehension and distrust among nations.

Mohamed H. A. Hassan

Third World Academy of Sciences,

Strada Costiera 11, 34014 Trieste, Italy

\section{Poetic pride in steps towards knowledge}

Sir - In their fascinating Insight Review "Inflammation and cancer" (Nature 420, 860-867; 2002), Lisa M. Coussens and Zena Werb traced knowledge of the relationship between inflammation and cancer back to the hypothesis proposed by the German physician Rudolf Virchow: that chronic inflammation caused by certain irritants can lead to cancer. This was later proved correct by two Japanese scientists, Katsusaburo Yamagiwa and Koichi Ichikawa, who showed that repeated painting of coal tar onto rabbits' ears causes carcinomas.

Yamagiwa was delighted with their results and composed a haiku: "Cancer was produced. Proudly I walk a few steps”. Their paper was originally written in German and published in a journal of the Imperial University of Tokyo in 1915. An English version was published in 1918.

In his Nobel lecture of 1966, Peyton Rous acknowledged the significance of this work. He wrote, "And then in 1918 came the epoch-making discovery by Yamagiwa and Ichikawa that tarring rabbit skin will cause tumors to arise. This opened an era of rewarding search for other chemical agents - and physical as well — which do the same. It is an era so far from done as to have been the main theme a few months ago of the International Cancer Congress held in Japan; and it was chosen with good reason since some of man's habits, many of the occupations through which he earns his living, and the mischances taking place in his own body can prove fatal through the growths they induce unless something is done to ward them off. All of these oncogens [sic] are initiating in character, and some can be dangerous promoters too, if the exposure to them is long."

Min-Liang Wong

Department of Veterinary Medicine, College of Veterinary Medicine, National Chung-Hsing University, Taichung 402, Taiwan 